1 Patterns of Mustelid gammaherpesvirus 1 (MusGHV-1) genital reactivation linked to

2 stressors in adult European badgers (Meles meles)

4 Ming-shan Tsai ${ }^{1 *}$, Sarah Francois ${ }^{2}$, Chris Newman ${ }^{1,3}$, David W. Macdonald ${ }^{1}$, Christina D. Buesching ${ }^{3,4}$

\title{
6 Affiliation
}

7 1. Wildlife Conservation Research Unit, Department of Zoology, University of Oxford, Recanati-Kaplan Centre, Abingdon Road, Tubney House, Tubney, Oxfordshire OX13 5QL, UK

9 2. Evolve.zoo, Department of Zoology, University of Oxford, Peter Medawar Building, South Park Road, Oxford, OX1 3SY, UK

3. Cook's Lake Farming Forestry and Wildlife Inc (Ecological Consultancy), Queens County, Nova Scotia, 12 Canada

13 4. Department of Biology, Irving K. Barber Faculty of Science, The University of British Columbia, Okanagan, Kelowna, British Columbia, Canada

*Correspondence: cindy150051@gmail.com

\section{Abstract}

18 Herpesvirus infections are common and mostly asymptomatic in vertebrates, but can result in 19 impaired reproduction. It is therefore important to understand infection patterns and associated risk 20 factors, particularly the effects of different stressors. Here we use Mustelid gammaherpesvirus 1 21 (MusGHV-1) infection in European badgers (Meles meles) as a host-pathogen wildlife model to study 22 the effects of a variety of demographic, social, physiological and environmental stressors on viral 23 reactivation in the genital tract. We collected 251 genital swabs from 151 free-ranging individuals 24 across 3 trapping seasons (spring, summer and autumn). We screened for MusGHV-1 using PCR and 25 explored possible links between genital MusGHV-1 reactivation and stressors, and their interactions, 26 using logistic regression. In adults, reactivation was more likely in males, especially those in poorer body condition during summer. In females, reactivation was more likely when living in social groups comprising a higher percentage of cubs, but counter to our predictions, recent lactation appeared not influential. In relation to age, reactivation was more common in individuals over 8 years old than among prime age adults, and among juveniles ( $<2$ years old), especially females and individuals in better body condition, likely due to early puberty. Environmentally, reactivation was more prevalent in summer when food abundance is typically low. Our results evidence age effects on MusGHV-1 reactivation; in juveniles MusGHV-1 shedding in the genital tract is likely related to primary infection, while in adults, genital MusGHV-1 reactivation from latency was associated with aging, social and/ or environmental stress. Keywords: Stress, herpesvirus reactivation, gammaherpesvirus infection, sexually transmittable diseases, STI, wildlife disease epidemiology 


\section{Importance}

41 The immuno-suppressive effects of elevated stress levels facilitate disease development, and can

42 ultimately cause host extinction at the population level, especially where diseases are transmitted

43 sexually. The impacts of stress on host-pathogen dynamics through disease, however, are still poorly

44 understood outside the laboratory or captive environments. Our study provides rare evidence from a

45 free-ranging wild mammal population that the infection dynamics of a common and sexually

46 transmittable gammaherpesvirus are linked to demographic, social, physiological and environmental

47 stress. We propose that the effects of stressors on STIs and viral reactivation are an important factor

48 to be taken into account in conservation efforts when working with vulnerable wildlife populations.

\section{Introduction}

Herpesvirus infection is common in vertebrates with most vertebrate herpesviruses belonging to 4 subfamilies, the Alphaherpesvirinae, Betaherpesvirinae, Gammaherpesvirinae and Deltaherpesvirinae

$53(1,2)$. Herpesvirus species are generally host-specific, but cross-species transmission is more frequent 54 than previously assumed $(3,4)$. After primary infection, the herpesvirus enters a latent stage in the 55 host cell (e.g. Iymphocytes in gammaherpesvirus infection), and can be reactivated repeatedly 56 throughout life by stress $(5,6)$, trauma (e.g. surgery:(7)) or primary co-infection with other pathogens (8). Reactivation is a process of viral lytic infection, which involves virus replication within the host cell, eventually destroying the cell and releasing infectious virions. Reactivation of herpesviruses usually occurs in the epithelial cells of mucosa that function as portals for external contact (e.g., mouth, nose,

60 eyes and genital tract), thus facilitating transmission. Reactivation is, however, typically asymptomatic or induces only mild disease, but can also promote development of severe diseases like cancer (9), depending on strain pathogenicity (10) and co-infection with other pathogens causing immunodeficiency (e.g. Human herpesvirus 8 and HIV (11)), and is associated with a higher risk of contracting co-infection with additional pathogens with high virulence (e.g. Chlamydia pecorum infection in koalas suffering from gammaherpesvirus reactivation (12)).

Chronic stress has proven a significant risk factor, causing immune system dysregulation. where corticosteroids inhibit the pro-inflammatory cytokine responses, allowing the virus to (re-)activate and undergo lytic proliferation unchecked (13). This link between elevated corticosteroid levels and herpesvirus reactivation has been proven experimentally (horses: (14); captive reindeer: (15) and through observation (e.g. humans: $(6,16)$; captive Grévy's zebras (Equus grevyi): (5), but has not been investigated in free-living wildlife populations.

74 Here, we use European badgers (Meles meles) as a wildlife model to investigate how different risk 75 factors and stressors affect herpesvirus reactivation. Badgers are seasonally breeding mustelids that 76 are commonly infected with the Mustelid gammaherpesvirus 1 (MusGHV-1: a large double-stranded 
DNA virus belonging to the Gammaherpevirinae, genus Percavirus), where prevalence of viral DNA in blood samples can reach up to $100 \%$ in the UK and in Ireland $(17,18)$, and $55 \%-82.5 \%$ in genital swab samples $(19,20)$. Gammaherpesvirus reactivation can cause severe disease in humans $(21,22)$ and domestic animals (23-25), and has increasingly been associated with illness in wildlife species (26-29). In badgers, previous research has linked otherwise asymptomatic MusGHV-1 reactivation in genital tracts to impaired female reproductive performance (20) and indicates that during the main mating season, adult males are at particular risk of genital MusGHV-1 reactivation. Nevertheless, the impact of social, physiological and environmental stress on MusGHV-1 reactivation has thus far not been investigated. Badgers are subject to a variety of stressors: faecal corticoid levels indicate that badgers experience seasonal variation in stress levels $(30,31)$, which may be due to variation in food availability $(30,31)$ and can result in mortality $(32,33)$. Sociologically, higher social group density is associated with female reproductive suppression (34,35), reduced body condition and fecundity (36), and increased bite wounding among male badgers (37). Furthermore, aging reduces tolerance to stress (38), specifically altering the balance of innate and acquired immunity in badgers (39), and increasing their risk of herpesvirus reactivation (20), as also observed in other carnivora species (40,41), sometimes resulting in chronic and continuous herpesvirus reactivation (42). Therefore metrics of body condition, especially reduced body-condition as a consequence of recent lactation $(30,43)$, can indicate that the individual may be experiencing physiological stress (30).

To evaluate the impact of potential stressors on genital MusGHV-1 reactivation, we conducted population-wide molecular screening using genital swabs taken from a free-ranging badger population in the south of England across 3 seasons (spring, summer and autumn). We investigated whether

99 environmental factors (i.e., season and social group size), host demographic parameters (i.e., sex, age 100 and lactation), and host health (i.e., body condition) affect risk of genital MusGHV-1 reactivation.

101

\section{Materials and methods}

103 Field data and sample collection

104 Samples were collected from 151 individual live-trapped badgers in Wytham Woods, Oxfordshire, UK $105\left(51 \circ 46^{\prime} 26^{\prime \prime} \mathrm{N}, 1{ }^{\circ} 19^{\prime} 19^{\prime \prime} \mathrm{W}\right.$; caught in May, September and November 2018 following the methodology 106 described in Macdonald et al. (44); for details see Table 1). All trapping and animal sampling protocols 107 were approved by the University of Oxford' Animal Welfare and Ethical Review Board. Trapping was 108 conducted under Natural England license (currently 2019-38863, Badger Act 1992) and all animal 109 handling procedures were carried out by qualified Personal Individual License (PIL) holders under 110 Home Office license (current PPL 30/3379, Animals (Scientific Procedures) Act 1986). For each capture, 111 we recorded sex, sett (i.e., communal den used by a badger social group) of capture, body condition 112 score (BCS, categorized as $1=$ very thin to $5=$ very fat), and lactational status (determined by teat 113 measurements of females in spring: (45)). Because each badger in Wytham is given an individual tattoo 114 at first capture (usually as a cub (46)), exact age (in years) was known for most (243 of 251) animals in 
115 the dataset. For the remaining 8 badgers first caught as adults, age was inferred by toothwear

116 according to the method described Bright Ross et al. (47). We defined 4 age classes:

117 i) juveniles $<2$ years old (cubs and yearlings were combined to increase sample sizes, as there was no

118 difference between Mus GHV-1 prevalence in cubs and yearlings: Fisher's exact test: $p$-value=0.7449);

119 and - based on sex-steroid levels (48); ii) young adults: $2 \leq \mathrm{x}<5$ years old; iii) old adults: $5 \leq \mathrm{x}<8$ years

120 old; iv) very old adults: $\geq 8$ years old. The number of cubs and adults resident in each sett was

121 estimated using minimum number alive (MNA) estimates $(44,47)$.

123 Sterile cotton tops with wooden shafts were used to swab the genital tracts of all females (cubs and

124 adults) and all males (except for very small male cubs in spring for animal welfare reasons), and stored

125 in $2 \mathrm{ml}$ sterile microcentrifuge tubes. All samples were frozen and stored at $-20^{\circ} \mathrm{C}$ immediately after 126 sampling. Badgers were released at their site of capture on the same day, after full recovery from 127 aneasthesia.

129 DNA extraction and purification

130 Each swab was reconstituted with $400 \mu$ l sterile double distilled water and vortexed gently at room 131 temperature for 10 minutes. A $200 \mu$ l aliquot was taken from the reconstituted swab fluids, and viral 132 DNA was extracted and purified using a commercial kit (DNeasy Blood and Tissue Kit, Qiagen) following 133 manufacturer's instructions. Purified DNA was then eluted in $100 \mu \mathrm{l}$ of the provided buffer.

Screening for MusGHV-1 DNA using polymerase chain reaction (PCR) and sequencing

136 The purified DNA was screened using a MusGHV-1-specific primer pair designed by King et al. 2004 137 (18), targeting 281 base pairs of the partial DNApol gene. For each reaction, a total of $20 \mu l$ PCR 138 solution was mixed with 10 $\mu$ l HotStartTaq Master Mix (Qiagen, containing 1 unit of HotStartTaq DNA 139 Polymerase, $12 \mu \mathrm{M}$ of $\mathrm{MgCl}_{2}$ and $1.6 \mu \mathrm{M}$ of each dNTP), $0.5 \mu \mathrm{M}$ of each primer, and $2 \mu$ l Coral Load gel 140 loading dye and $5 \mu \mathrm{LNA}$ template. Amplification conditions were kept at $95^{\circ} \mathrm{C}$ for 5 mins to activate 141 DNA polymerase, followed by 45 cycles of denaturation at $95^{\circ} \mathrm{C}$ for 45 seconds, primer annealing at $14260^{\circ} \mathrm{C}$ for 45 seconds, and chain elongation at $72^{\circ} \mathrm{C}$ for 1 minute, followed by a final extension at $72^{\circ} \mathrm{C}$ 143 for 10 minutes. Finally, the PCR products were loaded in 2\% agarose gel to check the amplification 144 results under UV light. Samples with positive results were then amplified again with substituted front 145 primer (5' CCA AGC AGT GCA TAG GAG GT 3') to generate longer sequences (771 base pairs). PCR 146 products were then purified and sent for genotyping using Sanger sequencing to confirm the identity 147 of produced amplicon. Sequences returned were then aligned by Clustal W method (49) and analyzed 148 for variation using MEGA X (10.1.7) (50). Representative sequences were selected and published on 149 GenBank under accession number MT332100 and MT332101 assigned. 
152 Statistical analyses were performed with the $R$ and $R$ Studio software (version 1.21335) (51).

153 Prevalence of genital MusGHV-1 DNA was calculated by dividing the number of PCR positive cases by 154 the total number of tested cases, and 5\% upper and lower confidence intervals were calculated using 155 the Wilson method (52). Logistic regression (gImer function, R package Ime4) with badger identity 156 (tattoo) number as a random effect was used to measure univariate effects of MusGHV-1 reactivation 157 in genital tracts with season, sex, age, age class, BCS, number of residents per sett, and percentage of 158 cubs per social group (calculated by sett), where we categorized these data on percentage of cubs per 159 group into low and high using $30 \%$ as the dividing point according to distribution of the data (Figure 160 S1). Effects of lactation were analyzed using Fisher's exact tests due to low sample sizes and 161 presented using odds ratios. The final multivariable model was selected through the manual 162 backwards selection method. Model residual diagnostics were conducted using R package DHARMa 163 (version 0.3.3.0). Model fit was established using area-under-receiver-operating characteristics (AUC) 164 (53). Kruskal-Wallis tests were used to compare genital MusGHV-1 positive and negative individuals of 165 different BCS. Because juveniles (especially cubs) are generally thinner than adults, and thus have a 166 different body condition distribution (Figure S2), we calculated a body condition index (BCI) as In(body 167 weight)/In(body length) (36)). We analysed the association of MusGHV-1 reactivation and individual 168 BCS for juveniles and adults separately. Linear models (Im function, R package Ime4) were used to 169 assess the association of age and MusGHV-1 reactivation prevalence.

\section{Results}

172 The overall prevalence of genital MusGHV-1 reactivation was 35.9\% (90/251, 95\% Cl: 30.2\% - 42.0\%), 173 and prevalence was generally higher in summer $(45 \%, 36 / 80)$ than in spring $(34.4 \%, 33 / 96)$ and 174 autumn (28\%, 21/75) (Table 2; Figure 1).

Age effects on seasonal and sex-specific patterns of genital MusGHV-1 reactivation There was strong evidence for an effect of age on genital MusGHV-1 where prevalence followed a U178 shaped age curve, being lowest for badgers at the age of 5 or 6 years old (Figure 2, quadratic term, 179 adjusted $R^{2}=0.683$, F-statistic $=12.83$ on 2 and $9 D F, p$-value $=0.002$ ). When divided by age classes, 180 prevalences in juveniles $(46.6 \%, 34 / 73)$ and very old badgers $(47.7 \%, 21 / 44)$ were higher than young 181 (30.9\%, 30/97) and old (13.5\%, 5/37) adults (Table 2). However, no effect of sex (logistic regression 182 analysis, $p=0.679$ ) was observed in the univariate analysis.

184 BCS effects on seasonal and sex-specific patterns of genital MusGHV-1 reactivation

185 Although adults with lower BCS had a higher probability of genital MusGHV-1 reactivation according 186 to our univariate analysis ( $p$-value=0.022, Table 2 ), when grouped by seasons and sex this relationship was only significant in adult males in summer (Kruskal-Wallis tests, $p$-value $=0.006$ ) (Figure 3 ). 
190 Genital MusGHV-1 reactivation was significantly more prevalent in females living in setts comprised

191 by $>30 \%$ cubs (logistic regression analysis, $p$-value $=0.002$ ), but there was no evidence for the absolute

192 number of adults, cubs nor the total number of badgers resident in each sett affecting reactivation

193 rates (Table 2).

195 Effects of recent reproductive success on female genital MusGHV-1 prevalence

196 There was no evidence for recent lactation affecting the reactivation rate in sexually mature females 197 in spring (Fisher's exact test, p-value=1) (Table 2).

Multivariable analysis of genital MusGHV-1 reactivation

200 Because the univariate analysis indicated that juveniles and adults appear to have different patterns 201 of reactivation, we separated these data to generate multivariable models of juveniles ( $n=73$ ) and 202 adults $(n=178)$. We included all variables initially for which there was any evidence for an effect in the 203 univariate analyses ( $p$-value $<0.10$, Table 2). The most parsimonious models for juveniles (Table 3 ) and 204 adults (Table 4) both had diagnostically acceptable (53) AUC area of 0.748 and 0.726 (Figure S3 and 205 S4), respectively. In juveniles, multivariable analysis showed that all females, and all juveniles with 206 higher BCS, were at particular risk of genital MusGHV-1 reactivation (Table 3). In adults, in contrast, 207 males are at a higher risk of MusGHV-1 reactivation than are females, where all adults experience the 208 highest reactivation risk in summer, and older ( $\geq 8$ years) badgers, and female living in setts with a 209 higher percentage (over 30\%) of cubs are at particular risk (Table 4).

211 Genetic diversity of MusGHV-1 in the Wytham badger population

212 We sequenced 5 MusGHV-1 positive PCR products of a partial DNA polymerase gene. All sequences 213 were trimmed to 694 base pairs and confirmed to be MusGHV-1 according to the NCBI online blasting 214 service, returning $98.7 \%(n=3)$ and $100 \%(n=2)$ nucleotide identity to the published MusGHV-1 215 sequence isolated from a badger in Cornwall, England (Accession number: AF275657).

\section{Discussion}

218 Herpesvirus reactivation triggered by stress has been widely confirmed naturally and experimentally 219 by corticosteroid injection in humans and domestic animals $(5,14)$. Linking stress and viral reactivation 220 in wildlife, however, is particularly challenging due to the difficulties of monitoring individual stress 221 levels in the field, and typically this relationship can only be confirmed experimentally by taking 222 subjects into captivity at least temporarily (15). Using indicators that have been linked to stress 223 hormone levels in previous studies can thus provide an informative way to study the relationship 224 between stress and herpesvirus reactivation in free-ranging wildlife.

226 Faecal corticosteroid measurements from badgers in Ireland (30) evidence higher stress levels in 227 summer likely associated with dry environmental conditions that result in lower earthworm availability 
228 (i.e., the badgers' main food type (46)); similarly, in our own study population, summer drought is an 229 established mortality factor due to starvation/ malnutrition $(32,33)$. This corresponds with our finding 230 that, in all adults, seasonal MusGHV-1 reactivation rates were highest in summer, but females tended 231 to have higher viral reactivation levels than males in spring - possibly due to reproductive stresses, 232 while the reverse was true in autumn (Figure 1) (30). Interestingly, however, we found no correlation 233 between BCS and MusGHV-1 reactivation across all seasons in females, implying that reduced body 234 condition was not necessarily indicative of physiological stress. In fact, Bright Ross et al. (subm) found 235 complex relationships between body-condition, survival and reproductive success in this same 236 population, where although breeding females lose condition, they often end up being no thinner than 237 non-breeding females as they were in much better condition in winter (i.e. before pregnancy/ 238 lactation).

240 From the perspective of male rates of reactivation, males with higher testosterone levels tend to be 241 thinner during spring and summer (54), but tend to mate more often (55). In our recent survey of Irish 242 badger populations (20), the high rate (over 80\%) of genital MusGHV-1 reactivation in adult males 243 during the peak (postpartum) mating season, from mid-January to mid-February, implies not only a 244 link to mating activity, but also a mechanism enhancing transmission. This corroborates another 245 finding in the same study that males with more spermatozoa have a higher prevalence of genital 246 MusGHV-1 reactivation (20); linking higher sexual activity to higher STI prevalence as reported also in 247 many other studies (56-59). We were unable to explicitly test effects relating to badger mating 248 behaviour in our study because we can not trap during late pregnancy and neonatal cub care, to avoid 249 stressing mothers or depriving cubs of maternal care. Nevertheless, although reactivation rate in 250 autumn, when food sources are most abundant, and badgers undergo a period of reproductive quiescence (60), and thus experience less implicit stress, was significantly lower compared only to summer, but not to spring. This suggests that other factor(s) (e.g. sex hormone cycles (61), oxidative 253 stress (62), genital microbiome (63) or bacterial co-infections) might also be affecting reactivation 254 rates, beyond the scope of our current study.

256 In terms of age class effects, the high genital reactivation rate detected in cubs and yearlings suggests 257 that badgers contract MusGHV-1 early in life, before reaching sexual maturity. Although MusGHV-1 258 reactivates repeatedly throughout life, reactivation tends to be less frequent in young and old adults 259 compared to adults in their prime, although rates increase in very old individuals. This matches 260 patterns in humans where most people become infected with herpes during their childhood/ 261 adolescence (e.g. 100\% and 70\% seroprevalence of EBV before age 14 in Hong Kong and the United 262 Kingdom (64)), then typically experience viral latency during their prime, but can suffer from 263 increasingly longer and more frequent herpesvirus reactivation that sometimes cause mild disease 264 (e.g., shingles (65) in old age due to lowered immune response $(66,67)$ ). 
Since vertical transmission of MusGHV-1 through the placenta is unlikely (20), and the potential for infection from the vaginal tract during parturition is equally low due to low genital MusGHV-1 reactivation rate in pregnant females (20), we hypothesise that cubs contract primary infection through close contact with virus-shedding conspecifics (20). Thereafter genital reactivation in cubs may arise after primary acute infection through non-sexual routes and subsequent latency, as observed in the murine model where Murine herpesvirus 4 (MuHV-4, also a gammaherpesvirus), inoculation in the nasal cavity results in acute infection in the respiratory tract and lungs and establishes latency in the spleen, but then reactivates in the vaginal tract 17-21 days after inoculation (61). MuHV-4 nasal cavity inoculation, however, does not result in reactivation in male genital tracts, and transmission is only possible from females to males. After sexual intercourse with virus-shedding female mice, the virus then replicates in the male penis for 3 weeks. Interestingly, also in badgers, female juveniles are at higher risk of MusGHV-1 reactivation in the genital tract than are males. Furthermore, juveniles in better body condition, regardless of sex, exhibit higher reactivation prevalence. Indeed, juvenile males in better body condition enter puberty earlier than thinner males (11 months compared to $22-28$ months: (57)). Once juveniles enter puberty they will experience an increased risk of contracting MusGHV-1 through sexual contact and/ or that their latent infection is

Our results also show that social group structure can affect prevalence of genital herpesvirus reactivation, particularly the proportion of cubs within a residential group. This trend was more apparent in females than in males. This may be because badger cubs generally carry higher pathogen burdens than adults $(68,69)$, and thus increase per capita immunity burden among all badgers resident in the respective sett (64).

\section{Conclusion}

Our study demonstrates - for the first time in the wild - the link between stress experienced by the host and latent virus reactivation. Amplified stress levels induced by human disturbance as well as food insecurity and more frequent catastrophic weather events arising from human induced rapid environmental change (HIREC) could therefore not only increase the risk of disease development, promotion of transmission within a population, but also negatively impact host reproductive fitness through latent virus reactivation in the reproductive tract (19). Careful monitoring of endemic latent virus infection as well as surveillance for possible newly emerging strains should be included when

\section{Acknowledgments}

301 The authors would like to thank Dr. Nadine Sugianto, Dr. Sil van Lieshout, Dr. Tanesha Allen, and Julius 302 Bright-Ross for assistance with sample collection, fieldwork and MNA data provision. MST would like 303 to thank the Ministry of Education in Taiwan and Lady Margaret Hall, University of Oxford, for 
304 scholarship support. The authors also thank Paul Johnson and Ta-Chun Liu for providing advice on 305 statistics. The authors claim no conflict of interests in the present work.

\section{Author Contributions}

308 Project conception: CBD,MST; samples collection: CBD,CN,MST ; laboratory work: MST; data 309 analysis: MST; writing and revision: MST,CBD,SF,DWM; All authors have read and approved the 310 manuscript. 
bioRxiv preprint doi: https://doi.org/10.1101/2021.01.19.427370; this version posted January 21,2021 . The copyright holder for this preprint (which was not certified by peer review) is the author/funder, who has granted bioRxiv a license to display the preprint in perpetuity. It is made available under aCC-BY-ND 4.0 International license.

313 Table 1: Details of swab sampling

\begin{tabular}{|c|c|c|c|c|c|c|c|c|}
\hline \multirow[b]{2}{*}{ Age class } & \multirow[b]{2}{*}{ Age } & \multicolumn{2}{|c|}{ Spring } & \multicolumn{2}{|c|}{ Summer } & \multicolumn{2}{|c|}{ Autumn } & \multirow[b]{2}{*}{ Total } \\
\hline & & Female & Male & Female & Male & Female & Male & \\
\hline Cub & 0 & 15 & 15 & 10 & 4 & 9 & 9 & 62 \\
\hline Yearling & 1 & 1 & 3 & 2 & 2 & & 3 & 11 \\
\hline \multirow{3}{*}{ Young adult } & 2 & 7 & 7 & 7 & 9 & 5 & 6 & 41 \\
\hline & 3 & 4 & 8 & 3 & 5 & 2 & 8 & 30 \\
\hline & 4 & 2 & 5 & 4 & 5 & 2 & 8 & 26 \\
\hline \multirow{4}{*}{ Old adult } & 5 & 2 & 1 & 6 & 1 & 3 & 1 & 14 \\
\hline & 6 & 3 & 1 & 3 & 1 & 3 & & 11 \\
\hline & 7 & & 2 & & 2 & & 2 & 6 \\
\hline & NA & 1 & 1 & 1 & 1 & & 2 & 6 \\
\hline \multirow{8}{*}{ Very old adult } & 8 & 4 & 4 & 4 & 3 & 1 & 3 & 19 \\
\hline & 9 & 2 & 1 & 2 & 1 & 1 & 1 & 8 \\
\hline & 10 & 3 & 1 & 3 & & 4 & & 11 \\
\hline & 11 & & & & & & & 0 \\
\hline & 12 & & & & & & & 0 \\
\hline & 13 & 1 & 1 & & 1 & 1 & & 4 \\
\hline & NA & & 1 & & & & 1 & 2 \\
\hline & Total & 45 & 51 & 45 & 35 & 31 & 44 & 251 \\
\hline
\end{tabular}


315 Table 2: Overview of genital MusGHV-1 reactivation prevalence and univariate logistic regression

316 analysis. Formula: MusGHV Variate + (1|Tattoo); number of observations: 251; groups by tattoo

317 number: 150

318

\begin{tabular}{lccccccc}
\hline & Positive & Total & Prevalence & Prevalence 95\% Cl & Odds ratio (OR) & OR 95\% Cl & P-value \\
\hline Sex & & & & & & & \\
$\quad$ Male & 45 & 130 & $34.62 \%$ & $27 \%-43.1 \%$ & 0.59 & $0.53-1.52$ & 0.679 \\
$\quad$ Female & 45 & 121 & $37.19 \%$ & $29.1 \%-46.1 \%$ & & & \\
Season & & & & & & & \\
$\quad$ Spring & 33 & 96 & $34.38 \%$ & $25.6 \%-44.3 \%$ & 1.37 & $0.7-2.69$ & 0.362 \\
$\quad$ Summer & 36 & 80 & $45.00 \%$ & $34.6 \%-55.9 \%$ & 2.16 & $1.08-4.33$ & 0.03 \\
$\quad$ Autumn & 21 & 75 & $28.00 \%$ & $19.1 \%-39 \%$ & &
\end{tabular}

Age class

$\begin{array}{lccccccc}\text { Juvenile }(<2 \text { years old }) & 34 & 73 & 46.58 \% & 35.6 \%-57.9 \% & 5.58 & 1.95-15.92 & 0.001 \\ \text { Young }(2-4 \text { years old }) & 30 & 97 & 30.93 \% & 22.6 \%-40.7 \% & 2.87 & 1.02-8.08 & 0.046 \\ \text { Old }(5-7 \text { years old }) & 5 & 37 & 13.51 \% & 5.9 \%-28 \% & & & \\ \text { Very old }(>7 \text { years old }) & 21 & 44 & 47.73 \% & 33.8 \%-62.1 \% & 5.84 & 1.92-17.78 & 0.002\end{array}$

Age

Age

Age $^{2}$

Body Condition ${ }^{a}$

Body condition score

Sett group size

$\begin{array}{ll}\text { Total } & 251 \\ \text { Adult } & 251 \\ \text { Cub } & 251\end{array}$

0.814

0.434

0.086

Cub percentage per sett

$\begin{array}{lcccc}\text { Low }(<30 \%) & 58 & 191 & 30.37 \% & 24.3 \%-37.2 \% \\ \text { High }(>30 \%) & 32 & 60 & 53.33 \% & 40.9 \%-65.4 \%\end{array}$

2.62

$1.23-4.83 \quad 0.002$

Lactational status $^{\text {cd }}$

$\begin{array}{lllll}\text { Not Lactated } & 3 & 10 & 30.00 \% & 10.8 \%-60.3 \% \\ \text { Lactated } & 6 & 18 & 33.33 \% & 16.3 \%-56.3 \%\end{array}$

1.17

$0.22-6.21$

\section{1}

320 a: Only adults were included in this analysis

321 b: Only females captured in spring were included in this analysis

322 c: Fisher exact test 
324 Table 3: Final general mixed effect model of multivariable logistic regression analysis for juveniles

325 Formula: MusGHV Sex + Body condition + (1|Tattoo); number of observations: 72; groups by tattoo

326 number: 48

327

\begin{tabular}{lcccccc}
\hline Group & Estimate & Standard error & z value & Adjusted OR & $95 \% \mathrm{Cl}$ & $\mathrm{p}$ value \\
\hline $\begin{array}{l}\text { (Intercept) } \\
\text { Sex }\end{array}$ & -1.226 & 0.7851 & -1.562 & & & 0.1184 \\
$\quad$ Female & & & & & \\
$\quad \begin{array}{l}\text { Male } \\
\text { Body Condition }\end{array}$ & -1.0519 & 0.5123 & -2.054 & 0.35 & $0.13-0.95$ & 0.04 \\
$\quad$ BCS & & & & & & \\
\hline
\end{tabular}

329 Table 4: Final general mixed effect model of multivariable logistic regression analysis for adults

330 Formula: MusGHV Sex + Season + AgeGroup + Cub percentage + Sex*Cub percentage + (1|Tattoo);

331 Number of observations: 178; Groups by tattoo number: 101

332

\begin{tabular}{|c|c|c|c|c|c|c|}
\hline Group & Estimate & Standard error & $z$ value & Adjusted OR & $95 \% \mathrm{Cl}$ & $p$ value \\
\hline (Intercept) & -0.9952 & 0.4859 & -2.048 & & & 0.04 \\
\hline \multicolumn{7}{|l|}{ Sex } \\
\hline \multicolumn{7}{|l|}{ Female } \\
\hline Male & 0.8171 & 0.4126 & 1.98 & 2.26 & $1-5.1$ & 0.048 \\
\hline \multicolumn{7}{|l|}{ Season } \\
\hline Spring & -1.037 & 0.4255 & -2.437 & 1.61 & $0.66-3.91$ & 0.297 \\
\hline Summer & -2.2692 & 0.6333 & -3.583 & 3.08 & $1.27-7.47$ & 0.013 \\
\hline \multicolumn{7}{|l|}{ Autumn } \\
\hline \multicolumn{7}{|l|}{ Age class } \\
\hline Young & -1.1084 & 0.468 & -2.368 & 0.35 & $0.15-0.82$ & 0.015 \\
\hline Old & -2.4001 & 0.7052 & -3.404 & 0.1 & $0.03-0.36$ & $<0.001$ \\
\hline \multicolumn{7}{|l|}{ Very old } \\
\hline \multicolumn{7}{|l|}{ Cub percentage per sett } \\
\hline \multicolumn{7}{|l|}{ Low $(<30 \%)$} \\
\hline High (>30\%) & 1.8903 & 0.6968 & 2.713 & 6.62 & $1.69-25.95$ & 0.006 \\
\hline \multicolumn{7}{|l|}{ Interaction } \\
\hline \multicolumn{7}{|l|}{ Female:Cub percentage } \\
\hline Male:Cub percentage & -2.3686 & 1.0492 & -2.258 & 0.09 & $0.01-0.73$ & 0.024 \\
\hline
\end{tabular}


336 1. Roizman B, Baines J. 1991. The diversity and unity of herpesviridae. Comp Immunol Microbiol Infect Dis 14:63-79.

338 2. Pellett PE. 2014. Trunkloads of Viruses. J Virol 88:13520-13522.

339 3. Woźniakowski G, Samorek-Salamonowicz E. 2015. Animal herpesviruses and their zoonotic potential for cross-species infection. Ann Agric Environ Med 22:191-194.

4. Brito AF, Pinney JW. 2020. Intrahost speciations and host switches shaped the evolution of herpesviruses. bioRxiv 418111.

5. Seeber PA, Quintard B, Sicks F, Dehnhard M, Greenwood AD, Franz M. 2018. Environmental stressors may cause equine herpesvirus reactivation in captive Grévy's zebras (Equus grevyi). PeerJ 2018:1-18.

6. Stowe RP, Pierson DL, Barrett ADT. 2001. Elevated stress hormone levels relate to Epstein-Barr virus reactivation in astronauts. Psychosom Med 63:891-895.

7. Grinde B. 2013. Herpesviruses: latency and reactivation - viral strategies and host response. J Oral Microbiol 5:22766.

8. Donofrio G, Cavirani S, Van Santen V, Flammini CF. 2005. Potential secondary pathogenic role for bovine herpesvirus 4. J Clin Microbiol 43:3421-3426.

9. Barton E, Mandal P, Speck SH. 2011. Pathogenesis and Host Control of Gammaherpesviruses: Lessons from the Mouse. Annu Rev Immunol 29:351-397.

10. Goodman LB, Loregian A, Perkins GA, Nugent J, Buckles EL, Mercorelli B, Kydd JH, Palù G, Smith KC, Osterrieder N, Davis-Poynter N. 2007. A point mutation in a herpesvirus polymerase determines neuropathogenicity. PLoS Pathog 3:1583-1592.

11. Zhang P, Wang J, Zhang X, Wang X, Jiang L, Gu X. 2020. Identification of AIDS-Associated Kaposi Sarcoma: A Functional Genomics Approach. Front Genet 10:1-12.

12. Stalder K, Vaz PK, Gilkerson JR, Baker R, Whiteley P, Ficorilli N, Tatarczuch L, Portas T, Skogvold K, Anderson GA, Devlin JM. 2015. Prevalence and clinical significance of herpesvirus infection in populations of Australian marsupials. PLoS One 10:1-15.

13. Morey JN, Boggero IA, Scott AB, Segerstrom SC. 2015. Current directions in stress and human immune function. Curr Opin Psychol 5:13-17.

14. Barrandeguy M, Vissani A, Olguin C, Becerra L, Miño S, Pereda A, Oriol J, Thiry E. 2008. Experimental reactivation of equine herpesvirus-3 following corticosteroid treatment. Equine Vet J 40:593-595.

15. das Neves CG, Mørk T, Thiry J, Godfroid J, Rimstad E, Thiry E, Tryland M. 2009. Cervid herpesvirus 2 experimentally reactivated in reindeer can produce generalized viremia and abortion. Virus Res 145:321-328.

16. Glaser R, Pearl DK, Kiecolt-Glaser JK, Malarkey WB. 1994. Plasma cortisol levels and reactivation of latent Epstein-Barr virus in response to examination stress.

Psychoneuroendocrinology 19:765-772. 
17. Sin YW, Annavi G, Dugdale HL, Newman C, Burke T, MacDonald DW. 2014. Pathogen burden, co-infection and major histocompatibility complex variability in the European badger (Meles meles). Mol Ecol 23:5072-5088.

18. King DP, Mutukwa N, Lesellier S, Cheeseman C, Chambers MA, Banks M. 2004. Detection of Mustelid Herpesvirus-1 Infected European Badgers (Meles meles) in the British Isles. J Wildl Dis 40:99-102.

19. Kent A, Ehlers B, Mendum T, Newman C, Macdonald DW, Chambers M, Buesching CD. 2017. Genital tract screening finds widespread infection with mustelid gammaherpesvirus 1 in the European badger (Meles meles). J Wildl Dis 54:133-137.

20. Tsai MS, Fogarty U, Byrne AW, O'keeffe J, Newman C, Macdonald DW, Buesching CD. 2020. Effects of mustelid gammaherpesvirus 1 (Musghv-1) reactivation in european badger (meles meles) genital tracts on reproductive fitness. Pathogens 9:1-17.

21. Dittmer DP, Damania B. 2013. Kaposi sarcoma associated herpesvirus pathogenesis (KSHV) An update. Curr Opin Virol 3:238-244.

22. Young LS, Yap LF, Murray PG. 2016. Epstein-Barr virus: More than 50 years old and still providing surprises. Nat Rev Cancer 16:789-802.

23. Chastant-Maillard S. 2015. Impact of bovine herpesvirus 4 (BoHV-4) on reproduction. Transbound Emerg Dis 62:245-251.

24. McLuckie AJ, Barrs VR, Lindsay S, Aghazadeh M, Sangster C, Beatty JA. 2018. Molecular diagnosis of Felis catus gammaherpesvirus 1 (FcaGHV1) infection in cats of known retrovirus status with and without lymphoma. Viruses 10.

25. Marenzoni ML, Sforna M, Stefanetti V, Casagrande Proietti P, Brignone L, Del Sero A, Falcioni F, Orvieto S, Tamantini C, Tiburzi A, Valentini S, Coletti M, Timoney PJ, Passamonti F. 2014. Detection of Equid herpesvirus type 2 and 5 DNA in uterine flushings of mares with reproductive disorders. Vet Microbiol 174:570-576.

26. Gagnon CA, Tremblay J, Larochelle D, Music N, Tremblay D. 2011. Identification of a novel herpesvirus associated with cutaneous ulcers in a fisher (Martes pennanti). J Vet Diagnostic Investig 23:986-990.

27. Tseng M, Fleetwood M, Reed A, Gill VA, Harris RK, Moeller RB, Lipscomb TP, Mazet JAK, Goldstein T. 2012. Mustelid herpesvirus-2, a novel herpes infection in northern sea otters (Enhydra lutris kenyoni). J Wildl Dis 48:181-185.

28. Nicolas de Francisco O, Esperón F, Juan-Sallés C, Ewbank AC, das Neves CG, Marco A, Neves E, Anderson N, Sacristán C. 2020. Neoplasms and novel gammaherpesviruses in critically endangered captive European minks (Mustela lutreola). Transbound Emerg Dis 1-13.

29. Abade dos Santos FA, Monteiro M, Pinto A, Carvalho CL, Peleteiro MC, Carvalho P, Mendonça $P$, Carvalho T, Duarte MD. 2020. First description of a herpesvirus infection in genus Lepus. BioRxiv Prepr https://doi.org/http://dx.doi.org/10.1101/2020.01.21.913723. 
30. George SC, Smith TE, Mac Cana PSS, Coleman R, Montgomery WI. 2014. Physiological stress in the Eurasian badger (Meles meles): Effects of host, disease and environment. Gen Comp Endocrinol 200:54-60.

31. Virgós E, Mangas JG, Blanco-Aguiar JA, Garrote G, Almagro N, Viso RP. 2004. Food habits of European badgers (Meles meles) along an altitude gradient of Mediterranean environments: A field test of the earthworm specialization hypothesis. Can J Zool 82:41-51.

32. Macdonald DW, Newman C, Buesching CD, Nouvellet P. 2010. Are badgers "Under The Weather"? Direct and indirect impacts of climate variation on European badger (Meles meles) population dynamics. Glob Chang Biol 16:2913-2922.

33. Nouvellet P, Newman C, Buesching CD, Macdonald DW. 2013. A Multi-Metric Approach to Investigate the Effects of Weather Conditions on the Demographic of a Terrestrial Mammal, the European Badger (Meles meles). PLoS One 8.

34. Woodroffe R, MacDonald DW. 1995. Female/Female Competition in European Badgers Meles meles: Effects on Breeding Success. J Anim Ecol 64:12.

35. Creel SR, Creel NM. 1991. Energetics, reproductive suppression and obligate communal breeding in carnivores. Behav Ecol Sociobiol 28:263-270.

36. Macdonald DW, Newman C, Stewart PD, Domingo-Roura X, Johnson PJ. 2002. Densitydependent regulation of body mass and condition in badgers (Meles meles) from Wytham Woods. Ecology 83:2056-2061.

37. Macdonald DW, Harmsen BJ, Johnson PJ, Newman C. 2004. Increasing frequency of bite wounds with increasing population density in Eurasian badgers, Meles meles. Anim Behav 67:745-751.

38. Hunter RG, McEwen BS. 2013. Stress and anxiety across the lifespan: Structural plasticity and epigenetic regulation. Epigenomics 5:177-194.

39. Van Lieshout SHJ, Badás EP, Mason MWT, Newman C, Buesching CD, Macdonald DW, Dugdale HL. 2020. Social effects on age-related and sex-specific immune cell profiles in a wild mammal: Immune cell profiles in a wild mammal. Biol Lett 16:0-6.

40. Dall'Ara P, Labriola C, Sala E, Spada E, Magistrelli S, Lauzi S. 2019. Prevalence of serum antibody titres against feline panleukopenia, herpesvirus and calicivirus infections in stray cats of Milan, Italy. Prev Vet Med 167:32-38.

41. Troyer RM, Beatty JA, Stutzman-Rodriguez KR, Carver S, Lozano CC, Lee JS, Lappin MR, Riley SPD, Serieys LEK, Logan KA, Sweanor LL, Boyce WM, Vickers TW, McBride R, Crooks KR, Lewis JS, Cunningham MW, Rovnak J, Quackenbush SL, VandeWoude S. 2014. Novel Gammaherpesviruses in North American Domestic Cats, Bobcats, and Pumas: Identification, Prevalence, and Risk Factors. J Virol 88:3914-3924.

42. Sebastiano M, Chastel O, De Thoisy B, Eens M, Costantini D. 2016. Oxidative stress favours herpes virus infection in vertebrates: A meta-analysis. Curr Zool 62:325-332. 
43. Woodroffe R, Macdonald DW. 1995. Costs of breeding status in the European badger, Meles meles. J Zool 235:237-245.

44. Macdonald DW, Newman C, Nouvellet PM, Buesching CD. 2009. An Analysis of Eurasian Badger (Meles meles) Population Dynamics: Implications for Regulatory Mechanisms. J Mammal 90:1392-1403.

47. Bright Ross JG, Newman C, Buesching CD, Macdonald DW. 2020. What lies beneath?

45. Dugdale HL, Davison D, Baker SE, Ellwood SA, Newman C, Buesching CD, Macdonald DW. 2011. Female teat size is a reliable indicator of annual breeding success in European badgers: Genetic validation. Mamm Biol 76:716-721.

46. Macdonald DW, Feber RE, Newman C, Buesching CD. 2015. Badgers in the rural landscape conservation paragon or farmland pariah? Lessons from the Wytham Badger Project. Wildl Conserv Farml, 2nd ed. 2:65-95. Population dynamics conceal pace-of-life and sex ratio variation, with implications for resilience to environmental change. Glob Chang Biol 26:3307-3324.

48. Sugianto NA, Newman C, Macdonald DW, Buesching CD. 2020. Reproductive and Somatic Senescence in the European Badger (Meles meles): Evidence from Lifetime Sex-Steroid Profiles. Zoology 141:125803.

49. Thompson JD, Higgins DG, Gibson TJ. 1994. CLUSTAL W: Improving the sensitivity of progressive multiple sequence alignment through sequence weighting, position-specific gap penalties and weight matrix choice. Nucleic Acids Res 22:4673-4680.

50. Kumar S, Stecher G, Li M, Knyaz C, Tamura K. 2018. MEGA X: Molecular evolutionary genetics analysis across computing platforms. Mol Biol Evol 35:1547-1549.

51. R-Development-Core-Team. 2019. R: A language and environment for statistical computing. $R$ Foundation for Statistical Computing, Vienna, Austria.

52. Wilson EB. 1927. Probable Inference, the Law of Succession, and Statistical Inference. J Am Stat Assoc 22:209.

53. Mandrekar JN. 2010. Receiver operating characteristic curve in diagnostic test assessment. J Thorac Oncol 5:1315-1316.

54. Buesching CD, Heistermann M, Macdonald DW. 2009. Seasonal and inter-individual variation in testosterone levels in badgers meles meles: Evidence for the existence of two endocrinological phenotypes. J Comp Physiol A Neuroethol Sensory, Neural, Behav Physiol 195:865-871.

55. Dugdale HL, Griffiths A, Macdonald DW. 2011. Polygynandrous and repeated mounting behaviour in European badgers, Meles meles. Anim Behav 82:1287-1297.

56. Ryder JJ, Pastok D, Hoare MJ, Bottery MJ, Boots M, Knell RK, Atkinson D, Hurst GDD. 2013. Spatial variation in food supply, mating behavior, and sexually transmitted disease epidemics. Behav Ecol 24:723-729. 
57. Munday PE, Pritchard G, Harris JRW, Taylor-Robinson D. 1983. Prevalence of chlamydial infection in promiscuous women. Sex Transm Infect 59:103-104.

58. White J, Richard M, Massot M, Meylan S. 2011. Cloacal bacterial diversity increases with multiple mates: Evidence of sexual transmission in female common lizards. PLoS One 6.

59. Poiani A. 2000. Sexually Transmitted Diseases: A Possible Cost of Promiscuity in Birds? Auk 117:1061-1065.

63. Urbaniak C, Lorenzi H, Thissen J, Jaing C, Crucian B, Sams C, Pierson D, Venkateswaran K,

60. Sugianto NA, Dehnhard M, Newman C, Macdonald DW, Buesching CD. 2021. A non-invasive method to assess the reproductive status of the European badger (Meles meles) from urinary sex-steroid metabolites. Gen Comp Endocrinol 301:113655.

61. François S, Vidick S, Sarlet M, Desmecht D, Drion P, Stevenson PG, Vanderplasschen A, Gillet L. 2013. Illumination of Murine Gammaherpesvirus-68 Cycle Reveals a Sexual Transmission Route from Females to Males in Laboratory Mice. PLoS Pathog 9.

62. Costantini D, Seeber PA, Soilemetzidou SE, Azab W, Bohner J, Buuveibaatar B, Czirják G, East ML, Greunz EM, Kaczensky P, Lamglait B, Melzheimer J, Uiseb K, Ortega A, Osterrieder N, Sandgreen DM, Simon M, Walzer C, Greenwood AD. 2018. Physiological costs of infection: Herpesvirus replication is linked to blood oxidative stress in equids. Sci Rep 8:1-10. Mehta S. 2020. The influence of spaceflight on the astronaut salivary microbiome and the search for a microbiome biomarker for viral reactivation. Microbiome 8:56.

64. Kangro HO, Osman HK, Lau YL, Heath RB, Yeung CY, Ng MH. 1994. Seroprevalence of antibodies to human herpesviruses in England and Hong Kong. J Med Virol 43:91-96.

65. Donahue JG. 1995. The incidence of herpes zoster. Arch Intern Med 155:1605-1609.

66. Stowe RP, Kozlova E V., Yetman DL, Walling DM, Goodwin JS, Glaser R. 2007. Chronic herpesvirus reactivation occurs in aging. Exp Gerontol 42:563-570.

67. Gouin JP, Hantsoo L, Kiecolt-Glaser JK. 2008. Immune dysregulation and chronic stress among older adults: A review. Neuroimmunomodulation 15:251-259.

68. Newman C, Macdonald DW, Anwar MA. 2001. Coccidiosis in the European badger, Meles meles in Wytham Woods: Infection and consequences for growth and survival. Parasitology 123:133-142.

69. Albery G, Newman C, Ross JB, Bansal S, Buesching C. 2020. Negative density-dependent parasitism in a group-living carnivore https://doi.org/10.1101/2020.06.15.153726.

70. Kelly TR, Karesh WB, Johnson CK, Gilardi KVK, Anthony SJ, Goldstein T, Olson SH, Machalaba C, PREDICT Consortium, Mazet JAK. 2017. One Health proof of concept: Bringing a transdisciplinary approach to surveillance for zoonotic viruses at the human-wild animal interface. Prev Vet Med 137:112-118. 


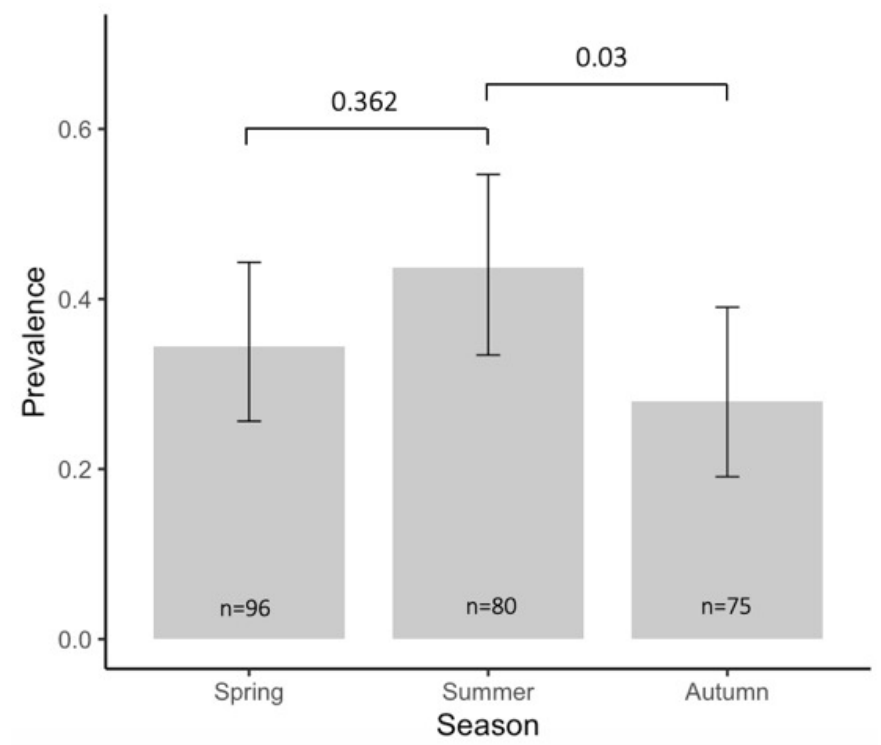

Figure 1: Difference of genital MusGHV-1 prevalence between seasons (Logistic regression analysis)

(A)

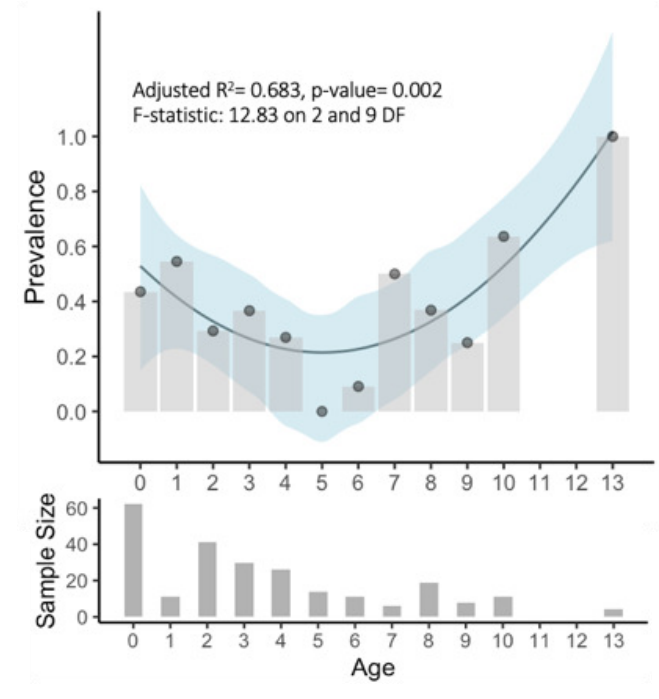

(B)

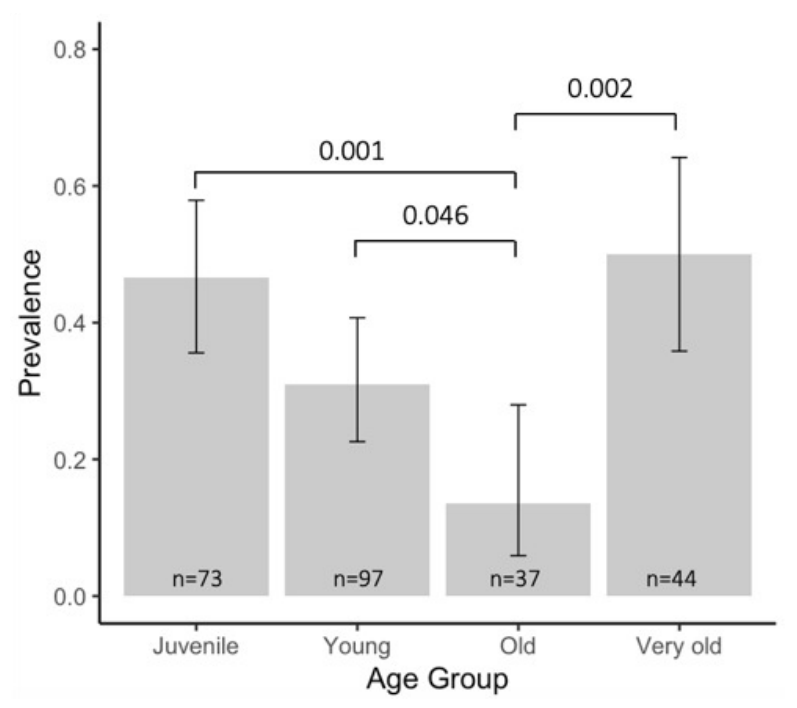

Figure 2: Difference of genital MusGHV-1 prevalence between exact age (A) and age groups (B) (Logistic regression analysis) 


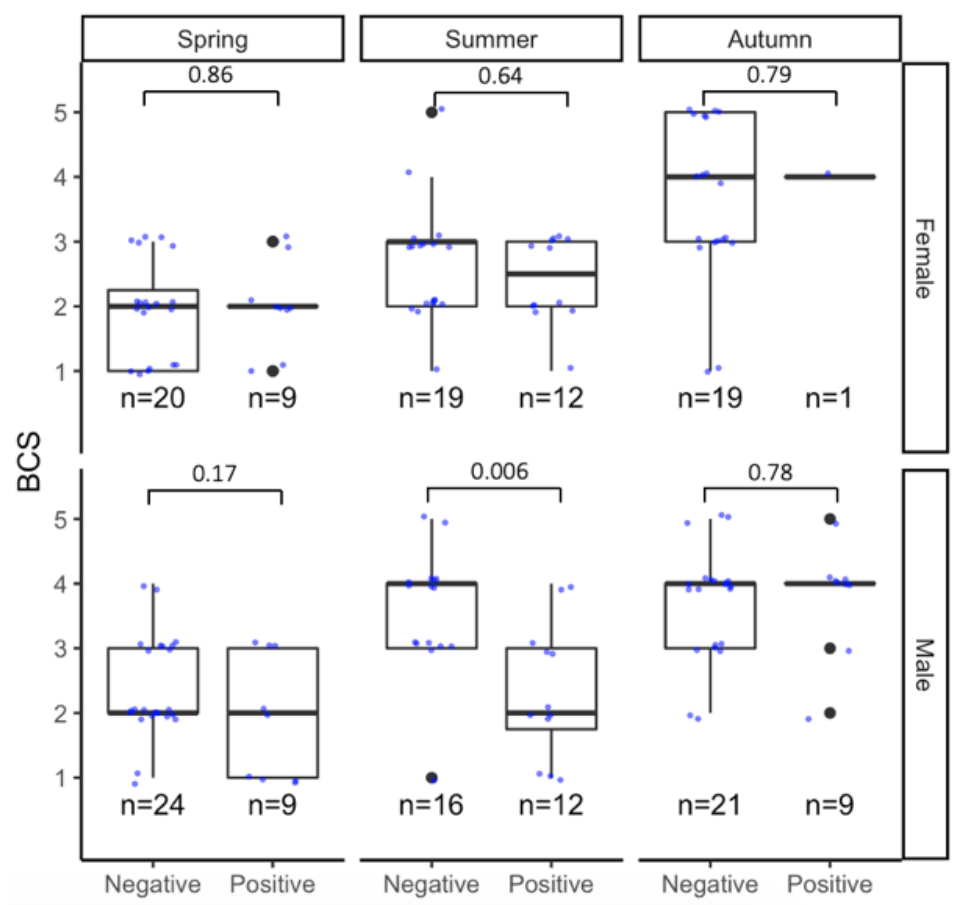

Figure 3: Comparison of body condition score difference of adults between genital MusGHV-1 reactivation status. The $\mathrm{p}$-values of each Kruskal-Wallis test results are showing above each box plot. 


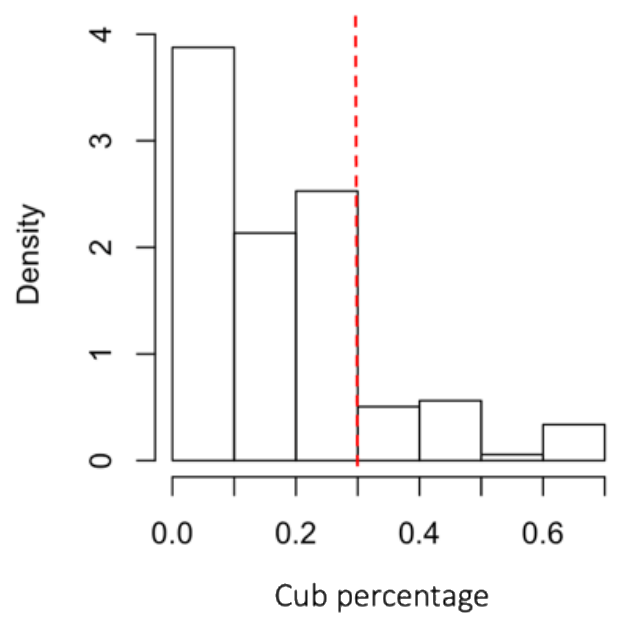

Figure S1: Data distribution of cub percentage $(n=251)$. The cutoff point $30 \%$ (red dashed line) is used to divide the tail and the distribution in the left.

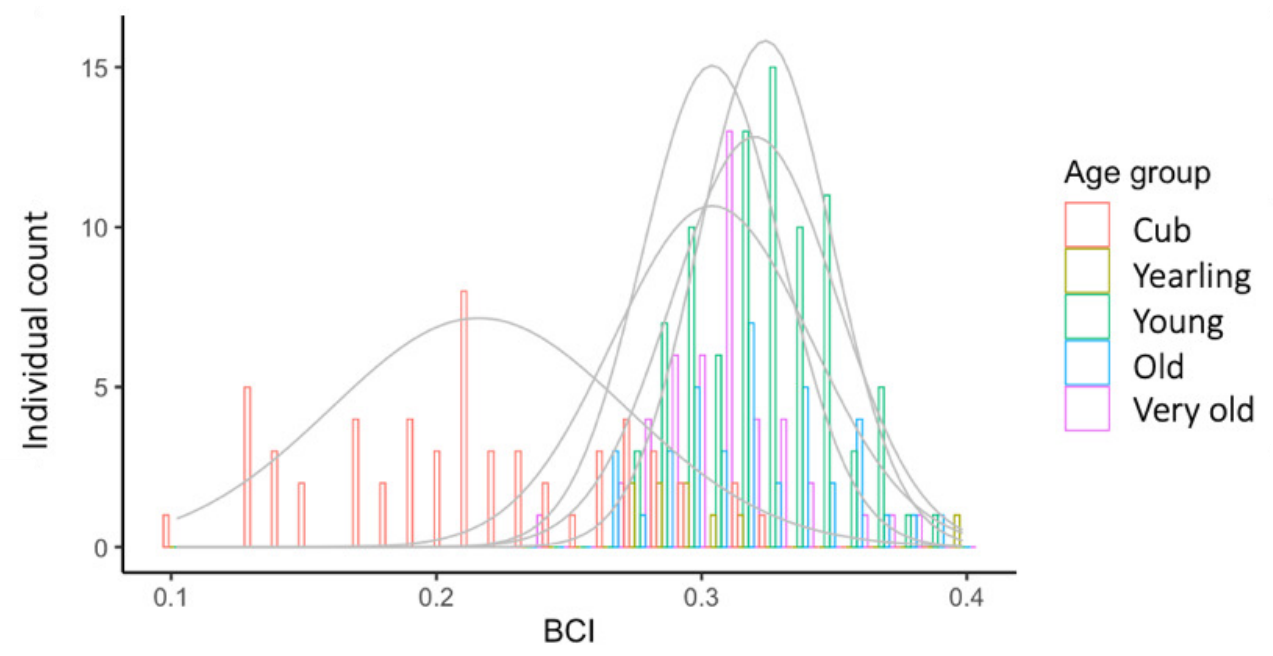

Figure $\mathrm{S} 2: \mathrm{BCl}$ data distribution by age groups showing distinct distribution of cub $\mathrm{BCl}$ comparing with other groups $(A)$ 
QQ plot residuals
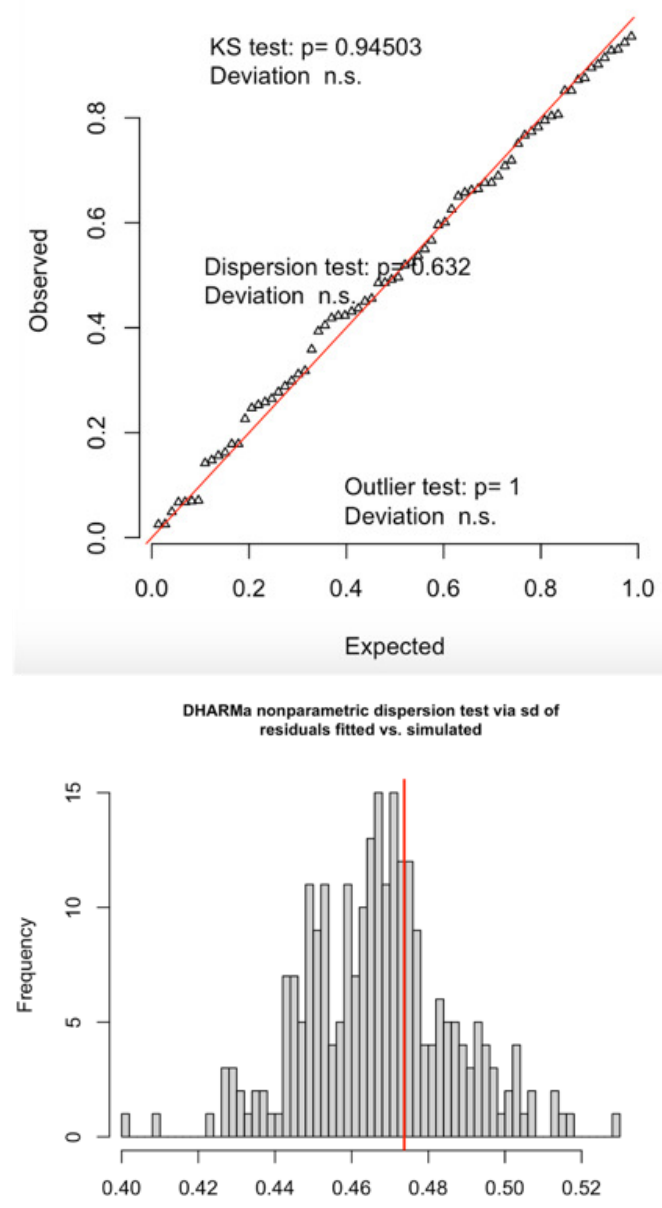

Simulated values, red line $=$ fitted model. $p$-value $($ two. sided $)=0.632$

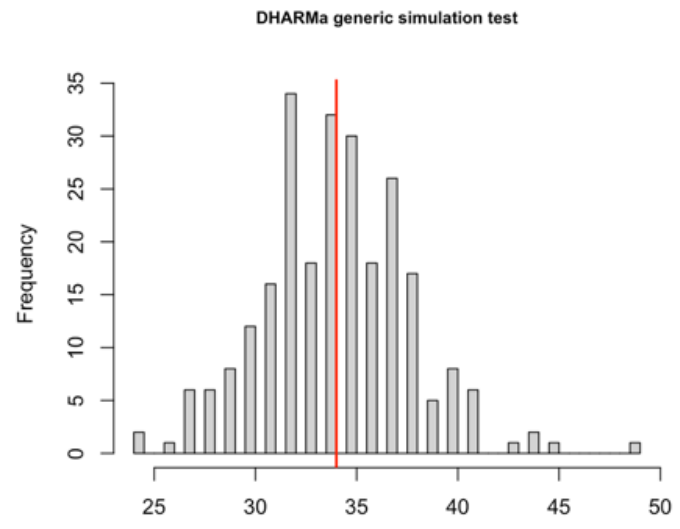

Simulated values, red line $=$ fitted model. $\mathrm{p}$-value $($ greater $)=0.588$
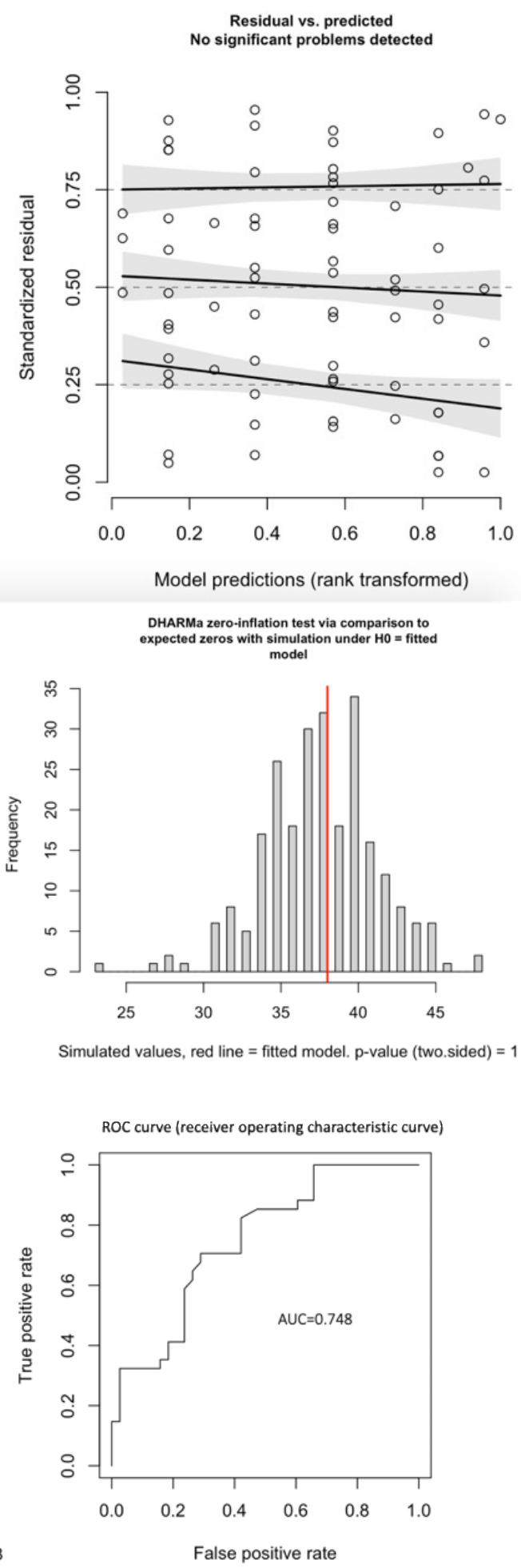

Figure S3: Diagnostic plot of the final multivariable logistic regression model of juvenile genital MusGHV-1 reactivation 

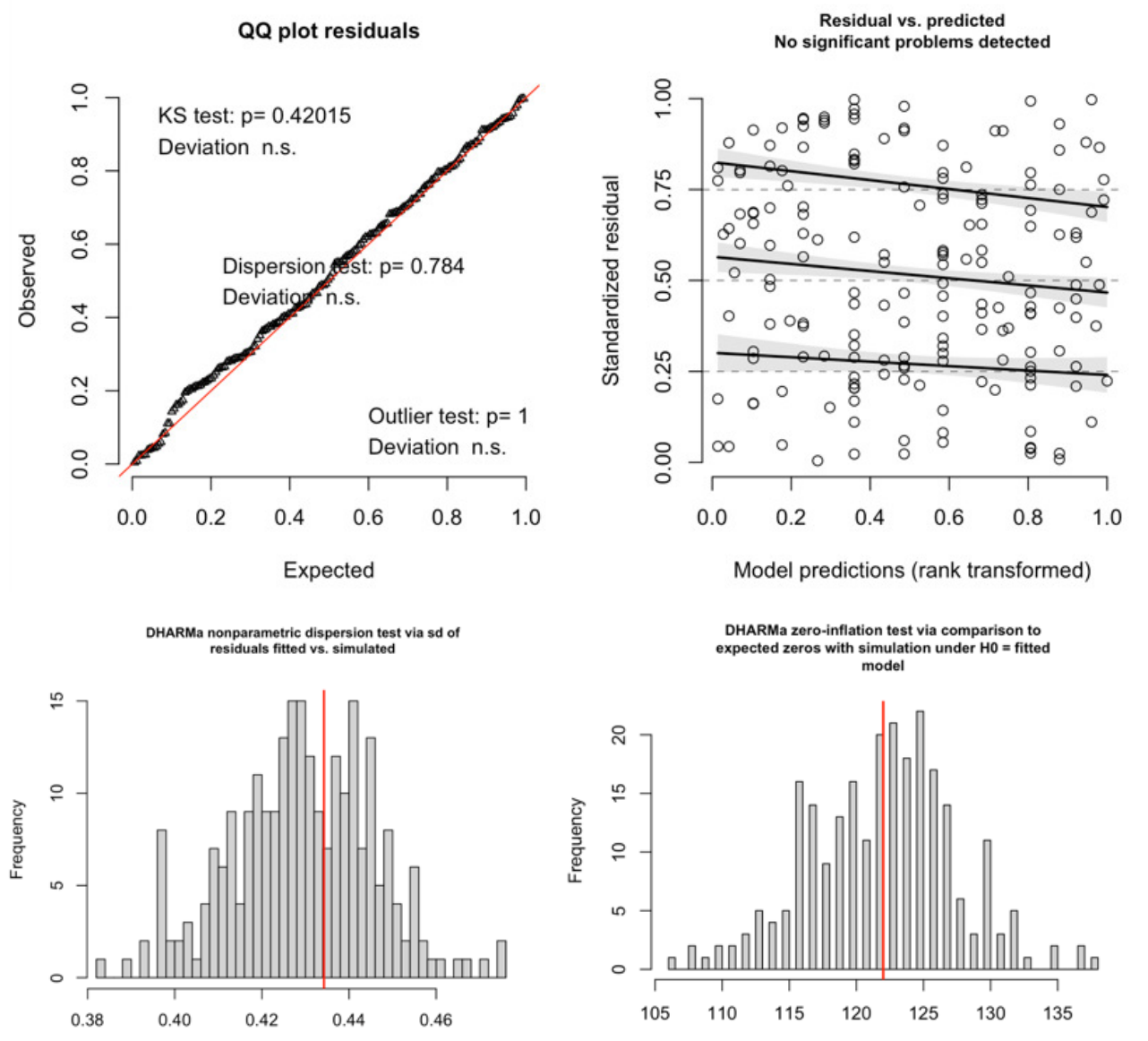

Simulated values, red line $=$ fitted model. $\mathrm{p}$-value $($ two, sided $)=0.784$

Simulated values, red line $=$ fitted model. $p$-value $($ two. sided $)=0.992$
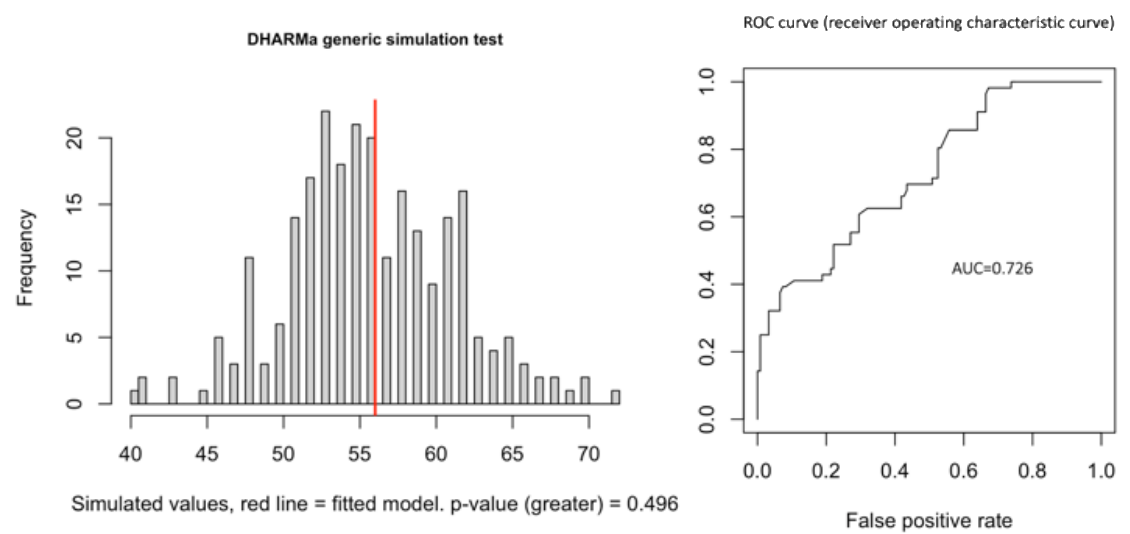

Figure S4: Diagnostic plot of the final multivariable logistic regression model of adult genital MusGHV-1 reactivation 